\title{
High Stakes
}

\author{
An Interview Study of Researchers' Motivations for \\ and Experiences of being Interviewed by Journalists
}

\author{
Benedicte Carlsen \& Hanne Riese
}

\begin{abstract}
Researchers are key sources of an increasing amount of research news in the media. Hitherto, the meagre empirical literature on researchers' media performances has been divided in two strands: one indicating that researchers are generally motivated to report their research in the media, and the other paradoxically reporting negative experiences of and conflict with journalists. The aim of the present study was to explore Norwegian researchers' motivations for participating in and experiences of journalistic interviews. We find that researchers' main reason for seeking media coverage is that they want their findings to be of use to society. This makes it essential to avoid errors or misleading framing of the news report. Despite strong motivations to do so, the researchers experience that communicating through the media is stressful and that their motivations for seeking media attention are in conflict with the motives of some research journalists. The study reveals a link between researchers' motivation for seeking media coverage and their experiences of conflict with journalists.
\end{abstract}

Keywords: research communication, science communication, news sources, researchers in the media, sociology of science

\section{Introduction}

The majority of us acquire most of our research-based knowledge through the media, and primarily through journalistic news or feature stories (Bell 1994; Castell et al. 2014; Wilson 1995). Researchers' experiences of journalistic interviews concerning their own research are of interest because researchers are the sources of research news. Nevertheless, empirical studies of what motivates researchers' media performances, and how researchers experience their meetings with journalists and the resulting news reports, are in short supply when compared to the large number of studies on the research stories themselves (Schäfer 2012). A meta-study conducted in 2009 found that most studies on research communication are based on surveys among journalists or researchers, a minority being qualitative interview studies (Schäfer 2012). Among the qualitative studies within research communications, few have explored researchers' views on the media specifically or in any depth (Besley \& Nisbet 2011). In general, the selection of researchers in the studies on researchers' views is remarkably skewed. While the great majority of studies describe the experiences and attitudes of natural scientists, very few include the views of social scientists or researchers from the humanities. 
From existing surveys we know that researchers are in contact with the media several times during their careers (Schäfer 2012), and that participating in journalistic interviews is the most common channel for reaching out to the public (Eide \& Ottosen 1994; Peters 1995; Peters et al. 2008). Furthermore, these surveys indicate that researchers are typically highly motivated for research communication through the media; the great majority see research communication through the media as something important. However, a review of two surveys among scientists in the UK and US indicates that while scientists often believe that being in the media and communicating through journalists is the most effective means of communicating with the public, they generally hold a negative view of science coverage and believe that science news reports are often confusing and often scare the public (Besley \& Nisbet 2011).

In 2013, we conducted a survey among Norwegian researchers from all major academic disciplines (Carlsen, Müftüoglu, \& Riese 2014). Norwegian researchers are encouraged by their institutions to participate in media interviews and to report them in national electronic databases. However, media interviews and other popular forms of research communication offer almost no academic merits or financial gain. Thus direct structural and economic incentives are lacking. Still the survey results indicate that the researchers have an average of two media appearances yearly, and more than $90 \%$ of the respondents agreed that research communication through journalistic interviews is important. Our study also found that a third of the researchers experience difficulties and find interactions with journalists frustrating, a finding that supports the reviewed studies from the UK and US.

In sum empirical studies seem to indicate that researchers are generally motivated to contribute to news stories, but still they seem to have a rather negative picture of how research news reports are presented in the media and understood by the public. This persistent participation in research communication despite that lack of incentives and negative experiences is a paradox.

One limitation of these quantitative studies is that they have investigated either motives or experiences, or at least analysed the two aspects separately. To explain the paradox of researchers' attitudes towards the media, we believe it is necessary to let the researchers tell their stories of "being in the media" and how motives and experiences are interconnected. We assume that the individual researcher goes through a process whereby the motives behind seeking media coverage influence what type of media institution or journalist is deemed acceptable, and then how the meeting with the journalist, and the resulting news story, is assessed by the researcher. This experience may, again, influence future motivation, choice of media channel or journalist, and so on. To understand such mental processes and how people look at the world, qualitative interviews are suitable (Connelly \& Clandinin 1990; Kvale 1996; Silverman 1985)

With the aim of better understanding the paradoxes surrounding motivations for and experiences of media interviews among today's Norwegian researchers, we conducted an in-depth, narrative-based interview study with researchers. Specifically, we were interested in exploring the underlying motives for communicating research results in the media, how researchers from various academic disciplines experience communicating with and through journalists, and how their motivations shape their media experiences. 


\section{Theoretical Framework and Analytical Approach}

Studies in the field of research communication in the media commonly describe encounters between journalists and researchers as a cultural clash (Reed 2001). In many ways, researchers and journalists represent conflicting professional cultures with colliding motives and aims, as well as conflicting views on control and ownership of the research news reports (Peters et al. 2008b). While both researchers and journalists are trained to reveal truths about the world (Kovach \& Rosenstiel 2007), there seem to be some small but significant differences regarding how the two groups believe the truth is best conveyed to the public. In 1995, Peters conducted a seminal study of research communication across several countries and found quite similar results on differences in motivation and views on the role of science news between researchers and journalists (Peters 1995; Peters et al. 2008a). One difference that has been confirmed in several studies is researchers' insistence on accuracy in reporting their findings, in contrast to journalists' aim of conveying an interesting and comprehensible story (Peters 1995; Radford 2007).

Whereas Peters describes scientists' encounters with journalists as a "struggle for control over the communication process" (Peters 1995, p. 42), studies of journalist-researcher interaction within science communication have often taken the perspective of the journalist. Descriptions of journalists' experiences offer insights into how the motives and cultural values of journalists contribute to shaping the encounter between the two professions. For example, one study of journalists across several countries finds that challenges due to the culture clash are frequent (Lassila-Merisalo 2011). Journalists worry about their news sources, for example that researchers have hidden agendas and are financially motivated. Thus they have a critical view of researchers' credibility and try to balance their stories by citing other opposing sources. Such strategies are in line with advice from journalism textbooks (Kovach \& Rosenstiel 2007). One Norwegian example is how, in his introductory book for science journalists, scholar of science journalism Harald Hornmoen emphasizes that journalists should be aware of possible financial agendas and the need to balance researchers' accounts with counter-arguments (Hornmoen 1999). Ideally then, science journalists should critically assess science news items before reporting them.

However, during the past fifteen years, parts of the traditional news press, such as newspapers, have been under financial strain and the labour market for journalists is undergoing substantial changes. For Norwegian journalists, getting permanent employment and specializing in one field has become difficult, as newspapers are increasingly forced to rely on all-round and freelance journalists. Media researchers have warned that it is difficult to live up to the ideals of critical and thorough journalism, particularly political and science journalism, under the current strained circumstances (Barnett 2002; Brumfiel 2009; Göpfert 2007)

In some contrast to studies on experiences of encounters between researchers and journalists that have reported conflict, the few in-depth studies of researchers' motivations, such as Smith et al.'s interview study among cancer researchers and journalists from the US (Smith et al. 2010), have found strong general support of communicating research through the media. The authors report that "Interviewees frequently articulated the value of mass media in communicating scientific information as being either obvious or unquestionable." (p. 212). In a survey of UK researchers' intentions to publicly disseminate their findings, Poliakoff and Webb find that researchers are more driven by their own attitudes than by what others expect them to do (Poliakoff \& Webb 2007). 
It has been argued that in order to understand researchers' motivations for seeking media coverage, it is vital to explore their professional role. Besides conducting the research, teaching and disseminating research in academic fora are traditionally seen as basic components of researchers' role, and in this endeavour researchers have a responsibility towards research participants to disseminate results truthfully (Kalleberg 2012). Kalleberg further argues that researchers are also expected to serve as experts and critical voices in relevant public discourses. Common categories of researchers' motives for media contact seem to be branding (i.e., increasing the visibility of the institution); accountability (i.e., legitimizing use of funding); education (i.e., educating the public about science); and enabling democracy and usefulness (i.e., informing the debate and helping the public or politicians make informed decisions) (Løvhaug 2011; Smith, Singer, \& Kromm 2010). These studies indicate that researchers' motivations for contributing to news stories are connected to their professional identity. They span from instrumental motives, which contribute to the legitimization of research, to motives grounded on researchers' professional role as experts who manage knowledge of relevance to society.

As mentioned above, our approach also leans on the somewhat contrasting studies of researchers' experiences as news sources. These suggest that even when researchers are fairly content with the news reports they are involved in, they still continue to be suspicious of journalists in general (Besley \& Nisbet 2011). It has been postulated that this phenomenon should be discussed in light of the notion that accuracy is a key component when news sources assess the credibility of news stories (Ørsten \& Burkal 2014).

Although it seems to have been established as a fact that difficulties in communication between researchers and journalists are connected to differences in professional cultures, little is known about how motives contribute to shaping the experiences researchers gain from meetings with journalists. Increased knowledge of the interplay of motives and experiences from the researchers' perspective may contribute to strengthening the dialogue between two professions that are rooted in different cultures.

A narrative interview study of how researchers experience the encounter with journalists is well suited to uncovering the relationship between motives for contributing to news stories and experiences of being interviewed. Such an approach allows us to uncover researchers' perspective on the dialogue with journalists, and to interpret these experiences within the context of knowledge on the journalists' perspective. "[..] narratives are one of the natural cognitive and linguistic forms through which individuals attempt to organize and express meaning and knowledge" (Kvale \& Brinkmann 2009, p153). Concentrating on researchers' narratives allows us to emphasize the meaning of their narratives in a social and temporal context. Thus, we can uncover how researchers regard their experiences as being shaped by their motives as well as by immediate concerns within the context of their meeting with the journalist. Explicitly taking the subjective point of view, the qualitative research interview lends itself to uncovering the meanings of experiences.

\section{Methods}

Interview participants were recruited among the academic staff at a medium-sized Norwegian university, and among all the researchers at a large private research institute. 


\section{Data collection}

We purposively selected participants among respondents in a survey conducted during the spring of 2013, the aim being to achieve variation in gender, age, career, discipline, and type of research institution they were employed at. In an in-depth study, the aim is not to include as many participants or carry out as many interviews as possible, as this would render the analysis superficial. Hence, when recruiting participants, we aimed for variation in experience and attitudes (according to their answers in the earlier survey), because we expected that findings based on the potential common themes across the interviews would be more robust (Patton 2005). We recruited participants in a continuous process of preliminary analyses and targeted recruiting. We stopped the interview process when we had conducted 17 interviews, because we had, at that point, material that was sufficiently rich and an amount that was manageable within our chosen analysis framework, and because the last few interviews did not seem to offer any new key findings (Carlsen \& Glenton 2011). For a profile of the participants, see Table 1.

Table 1. Profile of interview participants

\begin{tabular}{|c|c|c|c|c|c|}
\hline $\mathbf{N}$ & Sex & Academic field & Academic level & Institution & Interviews per year \\
\hline 1 & $\mathrm{~m}$ & Health sciences & senior & University & 15 \\
\hline 2 & $\mathrm{~m}$ & Social sciences & medium & University & 2 \\
\hline 3 & $f$ & Humanities & junior & University & 3 \\
\hline 4 & $f$ & Natural sciences & medium & University & 4 \\
\hline 5 & $\mathrm{~m}$ & Social sciences & medium & Private & 0 \\
\hline 6 & $f$ & Humanities & medium & University & 1 \\
\hline 7 & $\mathrm{~m}$ & Social sciences & senior & University & 12 \\
\hline 8 & $f$ & Social sciences & senior & University & 9 \\
\hline 9 & $\mathrm{~m}$ & Natural sciences & medium & Private & 2 \\
\hline 10 & $\mathrm{~m}$ & Natural sciences & senior & University & 2 \\
\hline 11 & $f$ & Social sciences & medium & University & 10 \\
\hline 12 & $f$ & Social sciences & medium & Private & 5 \\
\hline 13 & $\mathrm{~m}$ & Natural sciences & medium & Private & 10 \\
\hline 14 & $f$ & Health sciences & medium & University & 2 \\
\hline 15 & $\mathrm{~m}$ & Humanities & medium & University & 10 \\
\hline 16 & $\mathrm{~m}$ & Health sciences & senior & University & 1 \\
\hline 17 & $f$ & Natural sciences & junior & University & 5 \\
\hline
\end{tabular}

We initially contacted the participants by email, and subsequently telephoned them in order to arrange the time and place for the interviews. The interviews were audio recorded and were all conducted during the autumn term of 2013. BC conducted 11 interviews and HR conducted six interviews. The format of the interviews was open and explorative. We started each interview by informing the participant about the motivation for the research project and about the three main themes we wanted the participants to talk about: Their academic field and career, their overall experience with journalistic research communication, including positive and negative encounters, and media processes that they remembered in detail. We rarely had to prompt the participants to cover all of 
these themes and, in general, interrupted only to ask for clarifications and to check our interpretation of the participants' stories.

\section{Analysis}

Each interview was first summed up by the interviewing author and then discussed between the two authors as a preliminary analysis in order to plan further selection of participants. When 17 interviews had been conducted, we had the first five transcribed by a research assistant. Both authors read the transcribed interviews meticulously, listened through all of the interviews and noted the main emerging themes for coding. The authors discussed and agreed upon the key themes of the interviews and subsequently, one author (BC) coded and condensed the findings in a matrix as a cross-case analysis (Miles \& Huberman 1994), while the other author (HR) summed up each interview in condensed narratives representing the main findings in each interview. When comparing and sorting the narratives and categories that emerged from the material, we noted a high degree of consensus between the findings generated by the two approaches. Finally, the authors agreed upon a presentation of the main findings that combines the results from both analyses.

When interpreting the interview material, we kept in mind that the participants in the present interview study are not representative of any larger population, as participants in qualitative studies seldom are, and we therefore do not claim that our findings are in any way universal. However, we will argue that while not being universally generalizable, our findings are nonetheless valid and thus represent a genuine range of motives and experiences that can be found among researchers of today.

An additional aspect of the interview study that is worth reflecting upon is the fact that we, as academic researchers ourselves, are interviewing our peers, this having both advantages and disadvantages. While it enabled us to easily take on the role of confidante and secured our understanding of the context, e.g. the limitations and possibilities of the researchers' professional role, it may also have rendered us blind to some characteristics of the researchers and their roles. However, the clear advantage was that the interviewees provided honest and straightforward accounts of their views on and experiences of encounters with journalists. If an outsider position can be argued to strengthen the objectivity and emotional distance of the researcher, it can also be argued that only insiders can truly understand the nature of the question asked (Hammersley \& Atkinson 2007)

Although we had selected participants with a variety of characteristics, the interviewees conveyed a consistent set of experiences and attitudes regarding interaction with journalists, and views on the role of the researcher in society at large. In the following, we will attempt to depict the core of these findings and illustrate the key points using representative extracts from the interviews. Thus, all interviewees have not been cited and some interviews have been used more than others. Some details have been rewritten to ensure anonymity.

\section{Motivations for Research Communication through the Media}

Nearly all of our participants seemed to be, or at least to initially have been motivated to be interviewed by journalists. When telling us their stories of positive and negative interactions with journalists, the participants repeatedly returned to their reasons for 
conceding to media interviews. They listed several motives for, and the aims of, their interactions with journalists. Strikingly, most of the interviewees clearly felt that disseminating results through the media was an integrated part of the researchers' job.

That's why we're in this business, to make a difference. We're not doing research because we have some random idea that we are completely indifferent to the relevance of. What we want is to do research so that it will have some impact on society or on clinical practice or [...] (Participant 16)

Such utterances seem to imply that seeking media attention is not something researchers primarily do to concede to external demands placed on them by their research institution, funding agencies, or by other actors among the public. Rather, it is something they feel strongly obliged to do as researchers. Hence, the findings seem to indicate that research communication through the mass media has become an internalized idea among researchers of today.

The interviews consistently conveyed the view that communicating research through the media is an essential part of making research count, and being interviewed by journalists is the easiest way of accessing the media, thereby of reaching the public. The interviewees put considerable weight on the argument that if the research is relevant and important, it is also important that the findings be communicated. The researchers quite explicitly explained why this aim of spreading useful information seemed so imperative to them.

Firstly, we have a genuine interest in [research communication] and we believe it is important to convey this for the sake of nature, since we work with conservation, and we support conservation with our research. It's important to portray, for example, why one should preserve a waterway, well yes, that's because the results say such and such. These are enormous and important issues. [...] People can't do anything but rely on this kind of expertise, so that's why it's important that we actually convey this kind of expertise [...]. If you have results that you feel are important, then you have to get them out there. (Participant 9)

As this quote illustrates, many researchers felt compelled to communicate their research beyond academic circles. Scientific knowledge needs to be dispersed and to be of use to the general public, special groups, funding agencies and politicians, and the researchers felt responsible for this. Based on the theories and earlier studies of, among others, Løvhaug (2011) and Smith et al. (2010), we had not expected that usefulness would appear as the most important motivating factor. According to their models, we would have expected the researchers to put more weight on education of the public and accountability. However, these, and other motives also played a role, albeit a minor one, according to our informants.

Some participants mentioned the need to make a new research field, their institution or even themselves known to the academic world, as well as to potential funding agencies, and that media attention was encouraged by the PR departments or unit leaders at the research institutions, and sometimes by current funding agencies. Compared to writing their own popular science articles, interviews were seen as a more effective strategy for getting media coverage of the research, thereby attracting students, research funding, or increasing job opportunities. Some participants had experienced that media 
coverage resulted in new cross-disciplinary research, funding, and that their research reports were read more widely.

Where I work now, there's almost an agenda that we should be in the press. We have to talk about what we do and it's important to share our results. [...]

You might say there are commercial interests as well. We know that publicity is also good promotion for us. It can generate assignments too. (Participant 9)

Additionally, there were some references to having a sense of duty to report back to the tax payers what comes out of publicly funded research.

A few participants mentioned basic values of educating the public about research in general and thereby contributing to enhancing democracy. Others found it irritating to witness what they deemed to be uninformed or misinformed public debates about a topic they had more detailed knowledge about, and thus they wanted to inform the debate.

Motivation emerged as a key feature in the interviews, because it was both a prerequisite for, and a consequence of, the different encounters with the press. It both influences, and develops from, the encounters. Quite a few of the researchers also said that they enjoyed the attention media coverage entails, explaining that media coverage gave them a "good feeling", because many people would become familiar with the project or the subject they were working on. They enjoyed the feedback and the opportunity for communication with the public that they had experienced through media attention. Still, the personal benefits of media appearances were presented as meagre compared to the societal value, and they were not mentioned by all respondents.

Keeping in mind the fact that being driven by professional duties rather than by personal benefits is the expected and more politically correct answer, the intensity with which the researchers argued for the significance of research news lead us to have confidence in this finding. Also, given the incentive system of the research institutions, we are inclined to believe that this represents the interviewees' true feelings.

Motivating factors summed up according to salience:

1. Usefulness: It was consistently seen as important that research should inform and be of use.

2. Visibility of a research institution, research group, or research field in order to recruit students, researchers, or secure financing.

3. Accountability: Show taxpayers or funding agencies what results from their funding.

4. Attention can be fun. A feeling of meaningfulness (e.g., when friends and family suddenly see and understand what the researcher's job entails).

5. Democracy: The argument about educating the public about research in general.

\section{Researchers' Experiences: The Stakes are High}

As expected, based on earlier studies and our own recent survey, the great majority of our participants said that they had mostly had positive encounters with the media. However, as they reflected upon this they often seemed to best remember the negative exceptions to this norm. Clearly, leaving research dissemination to a journalist was not 
always experienced as successful. When researchers felt that the news report had been inaccurate, this led to frustration, especially because their motivation to enlighten the public means that it is essential that the information not be distorted.

I mean, what good is research if only other academics read the articles and have access to those facts, and most people don't know about it?[...] What worries me is if we get some results that you think are more than just someone sitting and arguing for one thing or the other, and if you think there actually is a kind of truth to it, and then they present it completely differently, or quite the opposite?! And especially when it's about issues like immigrants. In this case, I think that the majority population needs to know the way things actually are, because there is so much nonsense being written. (Participant 6)

The different motives of researchers compared to those of some of the journalists may explain why the researchers sometimes felt used or "misused" by the press. There was general agreement among the participants that the style and competence of journalists varied greatly and, thus, their experiences also varied. The participants categorized journalists and their encounters with them into two main types, and explained how what they perceived as the varying competence and attitudes of the journalists resulted in either "good" or "bad" research communication.

There's a very big difference in the quality of the journalists who call. [...]This journalist managed both to ask sensible questions and then to actually extract the essence of what I said and portray it in an interesting way. While other times it's just, well, you spend lots of time editing it, because you just cannot be quoted on what the journalist says that you said. (Participant 14)

The positive experiences were associated with what they saw as open, interested and competent journalists who listened and wrote news reports that were better written, and more interesting, than the researchers believed they could have written themselves. The meetings with "competent" journalists were sometimes described as a creative process where the outcome, in the form of a research news story, was a joint production between the researcher and the journalist that neither party could have produced on his/her own.

I've had many positive experiences. [...] You meet one of those open, competent journalists. They can improve my text a lot better than I could do myself, and we learn from each other in the process. It gets so much better than what I could've done alone, and what they could've done, because we have a good dialogue. [...] So that type of research-based news report, written by, clearly, incredibly talented journalists, that really is a joy! (Participant 12)

As we see here, among the researchers in our study, an acceptable result, or a "good" media story on research news, was defined as a simplified, but not skewed, account of research findings that combined the two motives of informing the public and arousing their interest.

On the other hand, the researchers mentioned "those with an agenda", or those whom they categorized simply as incompetent journalists. Encounters with this type of journalist, they felt, often resulted in incorrect and misleading articles, unless the researcher was given the opportunity to put a great deal of time and effort into rewriting 
the entire article. The researchers defined a "bad" experience with the media mainly as one resulting in a news article that misrepresented the scientific facts. Dealing with an "incompetent" or "tabloid" journalist, and thereafter being partly responsible for a faulty or tendentious news article, was commonly described as "disagreeable" or "intimidating". Such experiences also evoked strong feelings, which were described using terms such as "being fooled", "unfairness" and even "despair".

I think it's really bad if there's something that comes out wrong. And I think it's unfortunate because it seems like I'm the one who said something wrong too. And I haven't, but they take privileges and just write things. [...] I would not say that I have a relaxed attitude towards journalists. I always find it quite a nerve-racking event. I have to be constantly updated and up to scratch and everything has to be right. (Participant 13)

Deliberating over the varying quality of media coverage, interviewees were under the impression that some journalists failed to acknowledge the researchers' competence and role, or the importance of their research findings.

The larger newspapers, they want things to be correct, and they phone at eleven at night if they have to, "No, now I need to get this thing here. Am I quoting you correctly now if you say such and such...?" You get that very rarely with smaller newspapers and they like things a bit fresher, and often throw in some personal comments every now and then. [...] I think it's a bit strange. As a researcher, you have to, in a way, double underline the right answer and be very aware of not using the sources incorrectly [...]. "She said the sea level is rising by ten metres." "No, I did not say that, I said that there are incredibly large uncertainties, because if the large ice-sheets melt, we'll have a completely different situation than we have today, where only the small ice-sheets are melting and contributing to the sea level, so then you're talking about maybe one to three metres." So when you get the 'ten-metres' in your face, it's tough. I'm thinking, "That was not what I said!" (Participant 4)

The above quotations exemplify why, in spite of the participants' mostly positive experiences, being exposed in the media (the encounters with journalists, the resulting news stories and their aftermath in the form of reactions from other researchers or the general public) was frequently described as tense.

Although the more experienced participants were more relaxed about media exposure, and had experienced that the end result was normally acceptable, many continued to feel that they risked unpleasant or "degrading" experiences. They found it necessary to be "on guard" and, if possible, negotiate with the journalist in order to avoid unfortunate errors. The following is an account from an experienced health researcher who felt that he had neglected to be sufficiently alert in a recent meeting with a journalist. He felt that he, himself, had been ridiculed and the youths he had been studying had been stigmatized in the news report:

Even if you, as a researcher, try to interpret the data from a certain angle, you cannot know whether your article will be viewed or interpreted from a stigmatizing perspective. So $[\ldots]$ how should you do research and disseminate your findings knowing full well that you can't quite control the consequences of what you do, 
but that you might have an ethical obligation to think about, "what can these results be used for?" And who is it that might benefit from the results and who could you harm? (Participant 16)

A bad experience with the media had led this researcher to reflect on his ethical responsibility as a scientist. He has also put a lot of thought into the challenges of negotiating where the researcher's responsibility ends and that of the journalist begins.

The researchers told repeated stories of the ways in which journalist could be to blame for faulty research news, and why this was seen as problematic. Commonly, the researchers described bad experiences that they felt had occurred because the journalist had misunderstood the facts, or had deliberately put the facts in a misleading context, resulting in a faulty or distorted representation of the research.

There are lots of people who like to say that the climate will be wetter and wilder, but 'wilder' is a term that we never use, because we don't know whether there will be more storms. But the fact that it rains more, we do know. And when I was interviewed and I said, "Yes, what is the biggest challenge?" "It is rainfall and how it destroys infrastructure and we don't have good enough drainage [...]." And of course, the big headline, "Wilder climate', the researcher says." And the journalist was in the room, because he sat there writing and then he put it online right away, and I said, "I did not say 'wilder'." He said, "Yes, but more rain is 'wilder"'. "No, 'wilder' means stormy weather and more like 'Sandy' comes to Norway type hurricanes." "Yes, but it's catchier." So I said, "But that's not what I said." [...] It was his journalistic slant on it; that this meant 'wilder'. (Participant 4)

The participants mainly judged the media experience in relation to the resulting news stories and their consequences. When the news story did not reflect the research findings correctly, the main concern among all the researchers was the potential societal consequences that faulty media stories could have. By creating misunderstanding among the public, people could be misinformed or misguided, or a vulnerable group could be hurt. In their deliberations about what their responsibility would be and what the journalist's responsibility would be, the risk of hurting a weak third-party was a disturbing element, because the influence of the research on the researched is seen as part of the researcher's ethical responsibility.

I didn't realize, at the time, that lots of smaller newspapers get cases from each other. So the case from the first professional newspaper was picked up and it was like Chinese whispers. Suddenly, someone had posted a comment about how being a bit of a show-off was typical male behaviour, and my results do not show that. I have never said that, but it was slipped in in parenthesis and spread to umpteen newspapers that have picked up this case. [...] I mean, that detail, which was wrong, doesn't have much to say in the grand scheme of things, [...] but if I had researched whether a new treatment regimen works, for example, then it would have been a real crisis if it came out wrong, because if it takes hold then it may be of importance. [...] Then you can, for example, be worried that lots of people will stop taking their medications, that it actually has some kind of consequence for life and health. (Participant 14) 
How negative the experience of being misinterpreted is and to what degree the researcher is willing to overlook the misinterpretations seem to depend on whether or not the results are likely to have societal consequences.

I concluded that it could have a positive function. Unlike, for example, when health news is being distorted, and then it could, in a way, be detrimental to people perhaps, right? So then it becomes ethically problematic. But, in my case, I decided that it doesn't matter. As a researcher, one is very concerned about truth, but I suddenly became a little more pragmatic. It doesn't sound very professional, but it was, in a way, true enough and it has played a positive role. (Participant 3)

The participants often underlined that after going through a process of learning and adaption to the media, they could increase the likelihood of an open and respectful dialogue between themselves and the journalist, and thereby the chances of a "good" news report. However, in spite of this, the researchers' attitudes towards appearing in the media often continued to be characterized by ambivalence and a sense of risktaking. The interviewees found it important to inform the public, but at the same time they tended to feel nervous about getting the news story right. They found it important to keep some control over the news story so as to reduce the risk of misinforming the public (and, secondly, to avoid coming across as foolish). Thus, the interaction with the press was repeatedly described as a tense process, even though most of the time the results are acceptable.

\section{Summary and concluding remarks}

The findings support and elucidate the initial assumption drawn from our survey, namely that researchers are generally fairly satisfied with their media coverage, though they find the process difficult. For the researcher, the stakes are high.

To further explain the paradox surrounding researchers' experiences of media interviews, the findings can be summed up as follows:

1. Disseminating research through the media is internalized in researchers' professional role.

2. Their most important motive for contributing to news stories is to spread useful information.

3. Because researchers feel responsible for research news being useful and not causing harm, it is imperative to them that news stories present facts correctly and not in a distorted frame.

4. Researchers feel tense when in contact with the media, because in their experience some journalists lack competence or do not share the researchers' aim to provide correct information.

5. Thus, researchers' attitudes towards research communication in the media are characterized by ambivalence.

A common finding in our data was that disseminating research through the media is a duty that comes with the job, i.e., it is not predominantly something that the research 
institution, funding agencies, journalists or the public demand from researchers. The researchers' main motivation for seeking media coverage was that they wanted their findings to be of use, that is, to increase understanding or inform decisions and attitudes in society at large. This includes helping people make informed decisions about health and lifestyle, for example, as well as supporting policymakers.

Interestingly, Smith et al. find that, at least in the field of cancer research, the aim of making usable information available to the public is valued by researchers and journalists alike (Smith et al. 2010). When producing a research news story, the researcher and journalist need to work together to strike a balance between arousing attention and achieving simplicity and accuracy. It seems that common ground can be found in the usefulness of research news. Some of our participants emphasized how a good dialogue with a competent journalists had led to popularization of their research in news stories that had made their results interesting and understandable to the public without twisting the conclusions, thus, supporting their reasons for spreading information. The encounter between researcher and journalist is one between two professions with different frames of reference. Still, it may build on a common interest and therefore negotiation between the different frames is possible. Hence, sometimes the co-operation between researcher and journalist works and the result is "beautiful", as one of our participants put it.

Although the researchers in our study reported mainly having had positive media experiences, they also underlined that meetings with journalists sometimes had consequences that they deemed unfortunate, which they explained in term of the lack of competence among some journalists. This finding supports warnings from the field of journalism research; in the strained situation for journalism during recent years, it is plausible that the competence of some journalists who report research news is inadequate to fulfil the aim of assembling and verifying facts before reporting them in a meaningful and understandable context.

Owing to some unfortunate experiences, the researchers often feel tense during the processes surrounding media attention. When a news story misrepresents their research, they worry about possible negative consequences for the public. An interesting discovery in our study is therefore the ambivalence that characterizes the researchers' narratives concerning their negotiations with journalists. On the one hand, researchers may be enthusiastic about communicating their results through the media and they gradually learn to accept the journalistic form of writing, including the simplification of complex issues. On the other hand, they are worried about, and uncomfortable with, errors they feel routinely occur in news stories, or about their statements being framed in a misleading way.

Finally, we wish to stress that the most important and novel finding to emerge from the present study is the recognition of what is at stake for researchers. It should be emphasized that, across academic disciplines, researchers' primary reason for seeking media attention is not branding, not attracting funding, not accountability and not personal gain. Their primary motive is that they feel responsible for the overarching principle that research results should serve a purpose in society. It follows, therefore, that it is equally important to the researchers that the news stories correctly report the research findings.

The present study reveals a link between researchers' main motivations for seeking media coverage of their research findings and their sporadic experiences of conflict with journalists. We would argue that in this conflict lies the essence of the cultural clash 
between researchers and journalists, and that in this clash we may also find the key to improving research communication. Acknowledging what is at stake for the researchers as news sources may potentially inspire research institutions to better support researchers in their encounter with the media, and it may also have an instructive effect on the researchers and journalists themselves when they negotiate research news stories ${ }^{1}$.

\section{Note}

1. We would like to thank Professor Dag Elgesem for his valuable help and advice with the literature review and revision of the manuscript.

\section{References}

Barnett, Steven (2002) Will a crisis in journalism provoke a crisis in democracy? The Political Quarterly, 73(4), 400-408.

Bell, Allan (1994) Media (mis) communication on the science of climate change. Public Understanding of Science, 3(3), 259-275.

Besley, John C., \& Nisbet, Matthew (2011) How scientists view the public, the media and the political process. Public Understanding of Science, 22(6), 644-659.

Blach-Ørsten, Mark, \& Burkal, Rasmus (2014) Credibility and the media as a political institution. Nordicom Review. Special issue.

Brumfiel, Geoff (2009) Science journalism: Supplanting the old media? Nature News, 458(7236), 274-277.

Carlsen, Benedicte, \& Glenton, Claire (2011) What about N? A methodological study of sample-size reporting in focus group studies. BMC Medical Research Methodology, 11(1), 26.

Carlsen, Benedicte, Müftüoglu, Ingrid Birce, \& Riese, Hanne (2014) Forskning i media-Forskere om motivasjon og erfaringer fra medieintervjuer. Norsk Medietidsskrift(03), 188-208.

Castell, Sarah, Charlton, Anne, Clemence, Michael, Pettigrew, Nick, Pope, Sarah, Quigley, Anna, Shah, Jayesh Navin \& Silman, Tim (2014) Public Attitudes to Science 2014. London: Ipsos MORI Social Research Institute.

Connelly, F. Michael, \& Clandinin, D. Jean (1990) Stories of experience and narrative inquiry. Educational researcher, 19(5), 2-14.

Eide, Martin, \& Ottosen, Rune (1994) ‘Science journalism’ without science journalists: notes on a Norwegian media paradox. Public Understanding of Science, 3(4), 425-434.

Göpfert, Winfried (2007) The strength of PR and the weakness of science journalism. Journalism, Science and Society, 215.

Kalleberg, Ragnvald (2012) Sociologists as Public Intellectuals and Experts. Journal of Applied Social Science, 6(1), 43-52.

Kovach, Bill, \& Rosenstiel, Tom (2007) The elements of journalism: What newspeople should know and the public should expect. Three Rivers Press (CA).

Kvale, Steinar (1996) Interviews. An introduction to qualitative research interviewing. Thousand Oaks: SAGE Publications.

Løvhaug, Johannes W. (2011) Overlæreren i rampelyset. Universitetet i mediesamfunnet 1970-2011 (The head teacher in the limelight. The University in the media society 1970-2011). In John Peter Collet (Ed.) Universitetet i Oslo 1811-2011 (Vol. 7, pp. 367-509). Oslo: Unipub.

Miles, Matthew, \& Huberman, Michael. (1994) Qualitative data analysis: an expanded sourcebook. London: Sage.

Patton, Michael Quinn (2005) Qualitative Research Encyclopedia of Statistics in Behavioral Science: John Wiley \& Sons, Ltd.

Peters, Hans Peter (1995) The interaction of journalists and scientific experts: co-operation and conflict between two professional cultures. Media, Culture \& Society, 17(1), 31-48.

Peters, Hans Peter, Brossard, Dominique, de Cheveigné, Suzanne, Dunwoody, Sharon, Kallfass, Monika, Miller, Steve, \& Tsuchida, Shoji (2008) Science-Media Interface: It's Time to Reconsider. Science Communication, 30(2), 266-276.

Reed, Rosslyn (2001) (Un-)Professional discourse?: Journalists' and scientists' stories about science in the media. Journalism, 2(3), 279-298.

Schäfer, Mike S. (2012) Taking stock: A meta-analysis of studies on the media's coverage of science. Public Understanding of Science, 21(6), 650-663. 
Silverman, David (1985) Qualitative methodology and sociology: describing the social world. Gower Publishing Ltd.

Smith, Katherine Clegg, Singer, Rachel Friedman, \& Kromm, Elisabeth Edsall (2010) Getting Cancer Research Into the News: A Communication Case Study Centered on One U.S. Comprehensive Cancer Center. Science Communication, 32(2), 202-231.

Wilson, Kris M. (1995) Mass media as sources of global warming knowledge. Mass Comm Review, 22, 75-89.

BENEDICTE CARLSEN, PhD, Research Professor, Uni Research Rokkan Centre, Bergen, benedicte.carlsen@uni.no

HANNE RIESE, PhD, Associate Professor, Department of Education, Faculty of Psychology, University of Bergen, hanne.riese@psyhp.uib.no 